\title{
Molecular cloning and RNA interference-mediated functional characterization of a Halloween gene spook in the white-backed planthopper Sogatella furcifera
}

Shuang Jia, Pin-Jun Wan, Li-Tao Zhou, Li-Li Mu and Guo-Qing Li*

\begin{abstract}
Background: Ecdysteroid hormones ecdysone and 20-hydroxyecdysone play fundamental roles in insect postembryonic development and reproduction. Five cytochrome P450 monooxygenases (CYPs), encoded by Halloween genes, have been documented to be involved in the ecdysteroidogenesis in insect species of diverse orders such as Diptera, Lepidoptera and Orthoptera. Up to now, however, the involvement of the Halloween genes in ecdysteroid synthesis has not been confirmed in hemipteran insect species.

Results: In the present paper, a Halloween gene spook (Sfspo, Sfcyp307a1) was cloned in the hemipteran Sogatella furcifera. SfSPO has three insect conserved P450 motifs, i.e., Helix-K, PERF and heme-binding motifs. Temporal and spatial expression patterns of Sfspo were evaluated by qPCR. Sfspo showed three expression peaks in late second-, third- and fourth-instar stages. In contrast, the expression levels were lower and formed three troughs in the newly-molted second-, third- and fourth-instar nymphs. On day 3 of the fourth-instar nymphs, Sfspo clearly had a high transcript level in the thorax where PGs were located. Dietary introduction of double-stranded RNA (dsRNA) of Sfspo into the second instars successfully knocked down the target gene, and greatly reduced expression level of ecdysone receptor ( $E C R)$ gene. Moreover, knockdown of Sfspo caused lethality and delayed development during nymphal stages. Furthermore, application of 20-hydroxyecdysone on Sfspo-dsRNA-exposed nymphs did not increase Sfspo expression, but could almost completely rescue SFECR expression, and relieved the negative effects on nymphal survival and development.
\end{abstract}

Conclusion: In S. furcifera, Sfspo was cloned and the conservation of SfSPO is valid. Thus, SfSPO is probably also involved in ecdysteroidogenesis for hemiptera.

Keywords: Sogatella furcifera, Halloween gene, Ecdysteroidogenesis, RNA interference, Lethality, Development

\section{Background}

20-Hydroxyecdyone (20E), an active form of ecdysteroid, regulates insect postembryonic development and reproduction. Because of the absence of the enzymes involving in squalene synthesis, insects cannot synthesize $20 \mathrm{E} d e$ novo, and must obtain precursor sterols from their food [1], or their associated yeasts or fungi [2]. Rice planthoppers reportedly harbored yeast-like symbionts

\footnotetext{
* Correspondence: liguoqing001234@yahoo.com.cn

Education Ministry Key Laboratory of Integrated Management of Crop Diseases and Pests, College of Plant Protection, Nanjing Agricultural
} University, Nanjing 210095, China
(YLSs), mainly in mycetocytes formed by abdominal fat body cells [3-8]. The YLSs synthesize ergosta-5,7,24(28)trienol [9-12]. Ergosta-5,7,24(28)-trienol is then converted into cholesterol in planthoppers $[10,11]$.

The ecdysteroid biosynthesis in the prothoracic glands (PGs) begins from conversion of cholesterol into 7-dehydrocholesterol (7dC), mediated by a Rieske oxygenase Neverland [13,14]. The conversion of $7 \mathrm{dC}$ into 2,22,25-trideoxyecdysone (ketodiol) is a series of hypothetical and unproven reactions, and is called 'Black Box' [15]. In Drosophila melanogaster and Bombyx mori, CYP307A1/ A2 (SPOOK/SPOOKIER, SPO/SPOK) [16,17] and CYP6T3

\section{Biomed Central}

(c) 2013 Jia et al.; licensee BioMed Central Ltd. This is an Open Access article distributed under the terms of the Creative Commons Attribution License (http://creativecommons.org/licenses/by/2.0), which permits unrestricted use, distribution, and reproduction in any medium, provided the original work is properly cited. 
[18] have been proven to be involved in the 'Black Box'. Moreover, a paralog SPOOKIEST (SPOT, CYP307B1) was also found in CYP307 family [16,17]. RNAi mediated knockdown of spok in the PGs results in arrest of molting in $D$. melanogaster. Feeding two 3-oxo steroids, cholesta-4,7-diene-3,6-dione-14 $\alpha$-ol ( $\Delta 4$-diketol) and $5 \beta[\mathrm{H}]$ cholesta-7-ene-3,6-dione-14a-ol (diketol), in the RNAi-treated larvae triggered molting, enhanced amounts of ecdysteroids and induced 20E inducible genes [19]. These results indicate that $\Delta 4$-diketol and diketol are components of the ecdysteroid biosynthetic pathway and lie downstream of a step catalyzed by SPOK/SPO. SPO- and/or SPOK-like proteins had found in other insect species in Diptera such as Bemisia tabaci [20], in Coleoptera such as the red flour beetle Tribolium castaneum [21], in Hymenoptera such as Apis mellifera [22], in Lepidoptera such as Spodoptera littoralis [23], Manduca sexta [17] and Holcocerus hippophaecolus [24], in Orthoptera such as Schistocerca gregaria [25], and in Hemiptera such as Acyrthosiphon pisum [26]. Up to now, however, involvement of SPO in ecdysteroidogenesis has not been confirmed in other insect species except D. melanogaster and B. mori.

Most actions of $20 \mathrm{E}$ are mediated through their nuclear receptor, the ecdysone receptor (EcR) and its heterodimer partner ultraspiracle. Mutations in and RNA interference (RNAi) against EcR cause phenotypic defects and lethality in T. castaneum [27], and in Laodelphgax striatellus and Nilaparvata lugens [28]. Moreover, EcR expression is regulated by ecdysteroids through a positive feedback loop directly [29] or indirectly in D. melanogaster [30].

The white-backed planthopper, Sogatella furcifera, was a secondary pest of rice before 1980s. However, since the mid-1980s, its population dramatically increased following a nationwide adoption of hybrid rice in China [31]. $S$. furcifera causes serious damage to rice plants by sucking the phloem sap and blocking the phloem vessels, and by acting as a virus vector to transmit Southern rice blackstreaked dwarf virus [32-34]. Even though the complete genome sequence of $S$. furcifera is still unavailable, the transcriptome data have been published [35]. These data prompt us to identify and characterize the Halloween genes. Since dietary ingestion of double-stranded RNA (dsRNA) can effectively knock down target genes in planthoppers [36-39], our second goal in the present paper is to study the influence of the Halloween gene dsRNAs on the performance of $S$. furcifera nymphs, and the rescuing effects of $20 \mathrm{E}$ application on the negative influences of spo-dsRNA in the nymphs. Our results suggest that SfSPO play a critical role in ecdysteroidogenesis in S. furcifera.

\section{Results}

Molecular cloning and sequence analysis

Complete coding sequence of $S$. furcifera Halloween gene Sfspo (spo, cyp307a1) was obtained. Its open reading frame (ORF) encoded a putative protein with the length of 510 amino acid residue (Figure 1 ).

SPO sequence is similar to those from other insects. Insect CYPs have five insect conserved P450 motifs, i.e., WxxxR (Helix-C), GxE/DTT/S (Helix-I), ExxR (Helix-K), PxxFxPE/DRF (PERF motif) and PFxxGxRxCxG/A (hemebinding domain), where ' $x$ ' means any amino acid [40]. For SfSPO, Helix-C and Helix-I are not conserved. Helix- $\mathrm{C}$ had the amino acid sequence of $\mathrm{H} / \mathrm{YxxPR}$, and the amino acid sequence of Helix-I was GGHSA/V (Figure 1).

In insects, SPO belongs to CYP2 family. The N-terminus of SfSPO has one of the common characters in microsomal P450s, consisting many hydrophobic residues followed by a proline/glycine $(\mathrm{P} / \mathrm{G})$ rich region (Figure 1$)$.

\section{Temporal and spatial transcript profiles}

At our experiment temperature, S. furcifera second-, thirdand fourth-instar nymphs lasted an average of 2.0, 2.0 and 3.0 days. Sfspo showed three expression peaks in day 2 of second-instar, day 2 of third-instar and day 3 of fourthinstar nymphs. In contrast, the expression levels were lower and formed three troughs in the newly-molted second-, third- and fourth-instar nymphs (Figure 2A).

The spatial distribution of Sfspo on day 3 of the fourthinstar nymphs was also tested using qPCR. Sfspo clearly had a high transcript level in the thorax where PGs were located. Moreover, trace amounts of transcripts were found in the head and abdomen (Figure 2B).

\section{Dietary ingestion of dsRNA on expression of Sfspo and EcR genes}

During 6 days of continuous exposure to dsRNA-contained diet and 1 day after experiment, mRNA abundance of Sfspo in the surviving nymphs was examined by q-PCR. The mRNA level of $S f s p o$ in treated nymphs respectively reduced by $63.0 \%, 87.8 \%, 76.2 \%, 93.9 \%, 81.8 \%, 92.2 \%$ and $94.5 \%$, respectively, comparing to that in dsegfp-exposed controls (Figure 3A). This indicated that the RNAi-mediated knockdown of Sfspo was successful.

Since SfSPO is expected to act in other genes in the same signaling pathway, the possible effect of Sfspo knockdown was examined on the transcript level of $S f E c R$, which was one of $20 \mathrm{E}$ heterodimeric nuclear receptors and was regulated by $20 \mathrm{E}$ through a positive feedback loop directly [29] or indirectly in D. melanogaster [30]. As expected, during 6 days of continuous exposure to dsRNA-contained diet and 1 day after experiment, SfEcR expression levels in nymphs decreased by $76.0 \%, 88.3 \%, 71.7 \%, 88.8 \%, 82.1 \%$, $85.9 \%$ and $89.2 \%$ respectively, when compared with that in dsegfp-ingested planthoppers (Figure 3B).

\section{Effect of dsRNA on nymph survival}

Six day ingestion of dsRNA-contained diet caused nymphal lethality. The mortality reached up to $20 \%$ in nymphs that 


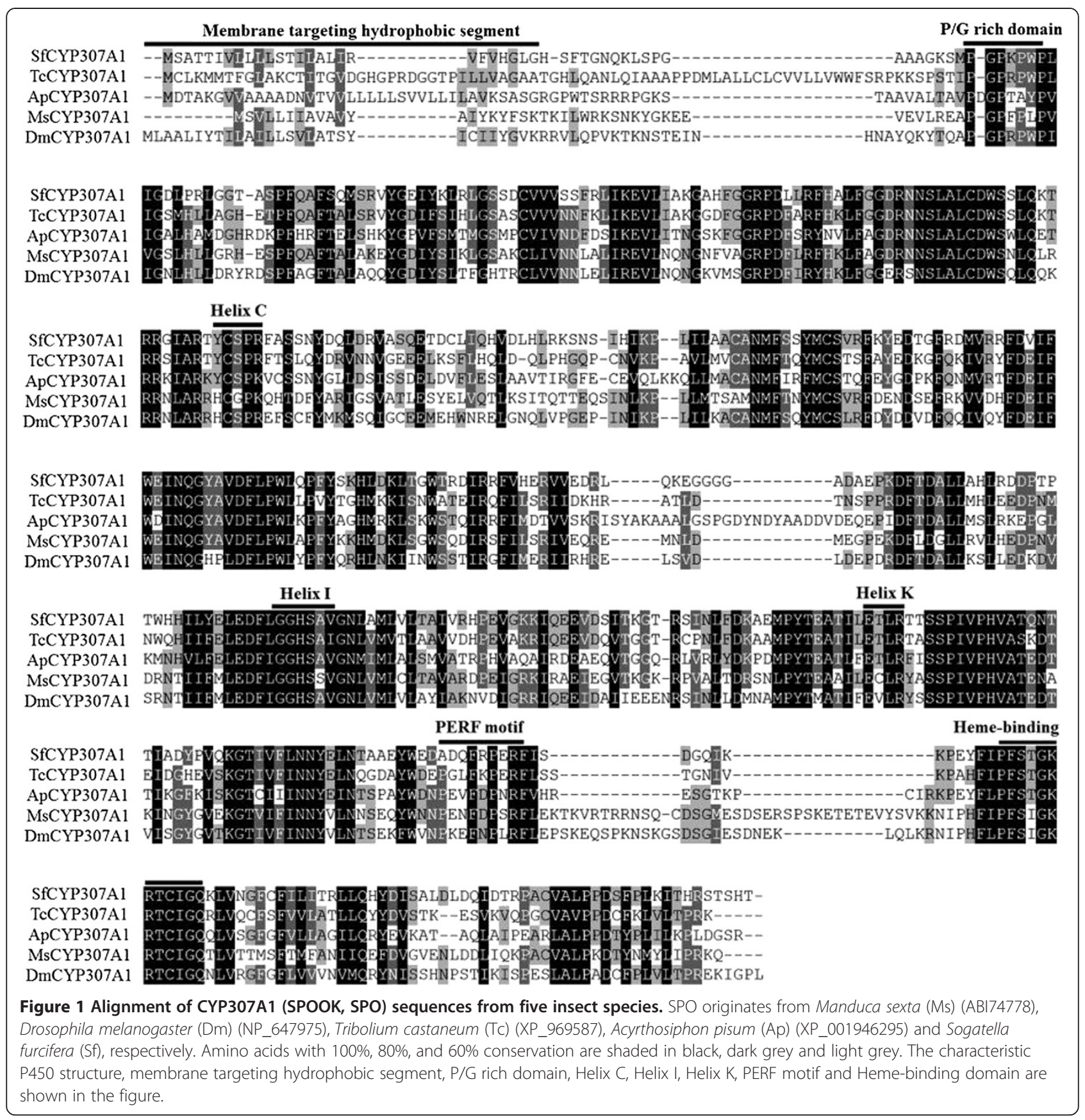

had ingested dsSfspo. In most cases, nymphs died during the period of ecdysis. In contrast, less than $5 \%$ of the planthoppers on normal or egfp-dsRNA-contained diets died (Figure 3C).

\section{Effects of dsRNA on nymph development}

Six day period of continuous exposure to dsRNA-contained diet significantly delayed nymphal development. $100 \%$ of the nymphs on normal and egfp-dsRNA-contained diets became the fourth instars after experiment. In contrast,

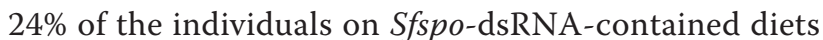
remained in the third-instar (Figure 3D).

\section{Rescue experiment}

Application of $300 \mathrm{pg}$ of $20 \mathrm{E}$ did not affect the expression level of Sfspo. In contrast, 20E application almost completely rescued $S f E c R$ expression at mRNA level. Moreover, 20E application to Sfspo-dsRNA-exposed nymphs almost completely overcame the negative effects on the survival and the development (Figure 4). 


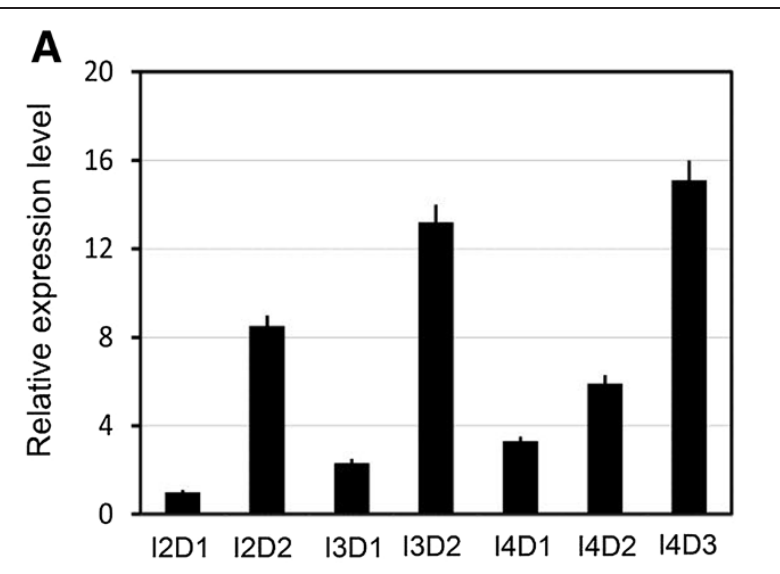

B

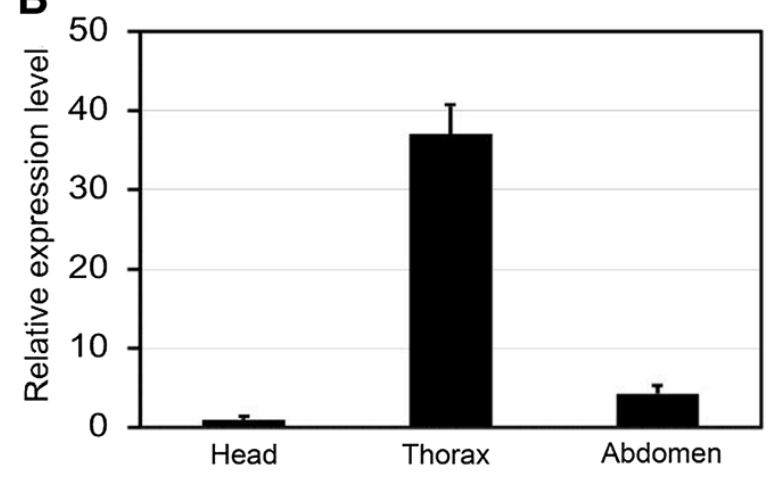

Figure 2 Graphic representation of the relative Sfspo transcript levels measured in the whole bodies of second-, third- and fourth-instar (I2D1, I2D2, I3D1, I3D2, I4D1, I4D2 and I4D3) nymphs at $24 \mathrm{~h}$ intervals $(\mathrm{A})$ and the head, thorax and abdomen of day 3 fourth-instar nymphs (B). For each sample, 3 independent pools of 5-10 nymphs were measured in technical triplicate using qRT-PCR. The values were calculated using the $2^{-\Delta \Delta C t}$ method. The relative expression levels were the ratios of relative copy numbers in individuals of specific developmental stage or specific body part to that in 12D1 or head. The columns represent averages with vertical bars indicating SE.

\section{Discussion}

Since the fundamental phenomena such as molting and metamorphosis are conserved during arthropod evolution, the Halloween genes are expected to be well conserved in insects [23,25,26,41-44], and in other arthropods [1,45]. In the present paper, the presence of Sfspo was demonstrated in S. furcifera. The primary structure of SfSPO has three insect conserved P450 motifs, i.e., Helix-K, PERF and heme-binding motifs. Similar structural characters have been documented in SPO- and SPOK-like proteins from other insect species of diverse orders such as Diptera $[16,17,20]$, Coleoptera [21], Hymenoptera [22], Lepidoptera $[17,23]$, Orthoptera [25], and Hemiptera [26]. The $\mathrm{N}$-terminus of SfSPO has one of the common characters in microsomal P450s, consisting many hydrophobic residues followed by a proline/glycine (P/G) rich region. Consistent with the structural features, SPO is detected in endoplasmic reticulum (ER) when the corresponding gene is transfected to Drosophila S2 cells $[17,46]$. Moreover, Sfspo showed three expression peaks in late second-, third- and fourthinstar stages. In contrast, the expression levels were lower and formed three troughs in the newly-molted second-, third- and fourth-instar nymphs. In the fourth-instar nymphs of the brown planthopper $N$. lugens [47] and in the sixth-instar larvae of a lepidopteran species $S$. littoralis, the level of ecdysteroid showed a peak in the later instar stage. In $D$. melanogaster larval stage, expression patterns of Dmspo gene undergoes dramatic fluctuations, consistent with circulating ecdysteroid quantity in the haemolymph: being high in late seconds, low in early third and high in late thirds [17]. Furthermore, we found in this study that Sfspo clearly had a high transcript level in the thorax where PGs were located. Similarly, Dmspo is expressed primarily in the PG cells of the ring gland in larval and adult stages [17]. Thus, the structural features and temporal and spatial expression patterns suggest that SfSPO might be involved in the ecdysteroidogenesis in S. furcifera.

The suggestion is further confirmed by three lines of experimental evidence in the present paper. Firstly, RNAi-mediated knockdown of Sfspo in S. furcifera reduced the expression level of $S f E c R$ at the mRNA level. In other insect species, mutations in or RNAi against the Halloween enzymes caused a decrease in ecdysteroid titers [23,25,26,44,46,48-51]. Moreover, the expression of $E c R$ gene was regulated by ecdysteroids through a positive feedback loop in D. melanogaster $[29,52]$. Accordingly, it can be hypothesized that RNAi-mediated knockdown of Sfspo negatively affects ecdysteroidogenesis in S. furcifera, and subsequently down-regulated $S f E c R$ expression in S. furcifera. Consistent with the hypothesis, our rescue experiment revealed that $20 \mathrm{E}$ application almost completely rescued $S f E c R$ expression in nymphs that had ingested dsSfcyp307a1.

The second line of experimental evidence is that RNAimediated knockdown of Sfspo in S. furcifera caused phenotypic defects similar to insects whose ecdysteroid synthesis was disturbed or whose ecdysteroid-mediated signaling had been inhibited $[53,54]$. In the present paper, we found that ingestion of dsSfspo caused nymphal lethality and developmental delay. Since the average second- and third-instar periods of the nymphs in our experimental conditions was respectively about 2 days and the deaths mainly occurred in the sixth day after dsRNA exposure, it means that the nymphs died during the third ecdysis. In fact, we also observed many abnormal and lethal ecdysis individuals on Sfspo-dsRNA contained diet, whereas most of the larvae on control normally molted. Similar phenomena have been observed in other two rice planthoppers, L. striatellus and N. lugens, in which silencing of EcR expression by in vivo RNAi to inhibit ecdysteroid-mediated signaling generated phenotypic defects in molting and 


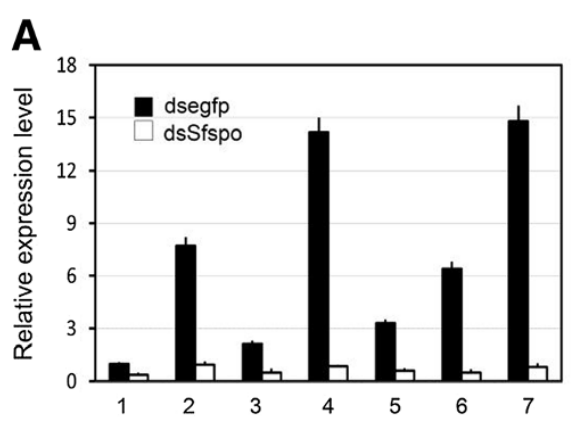

B
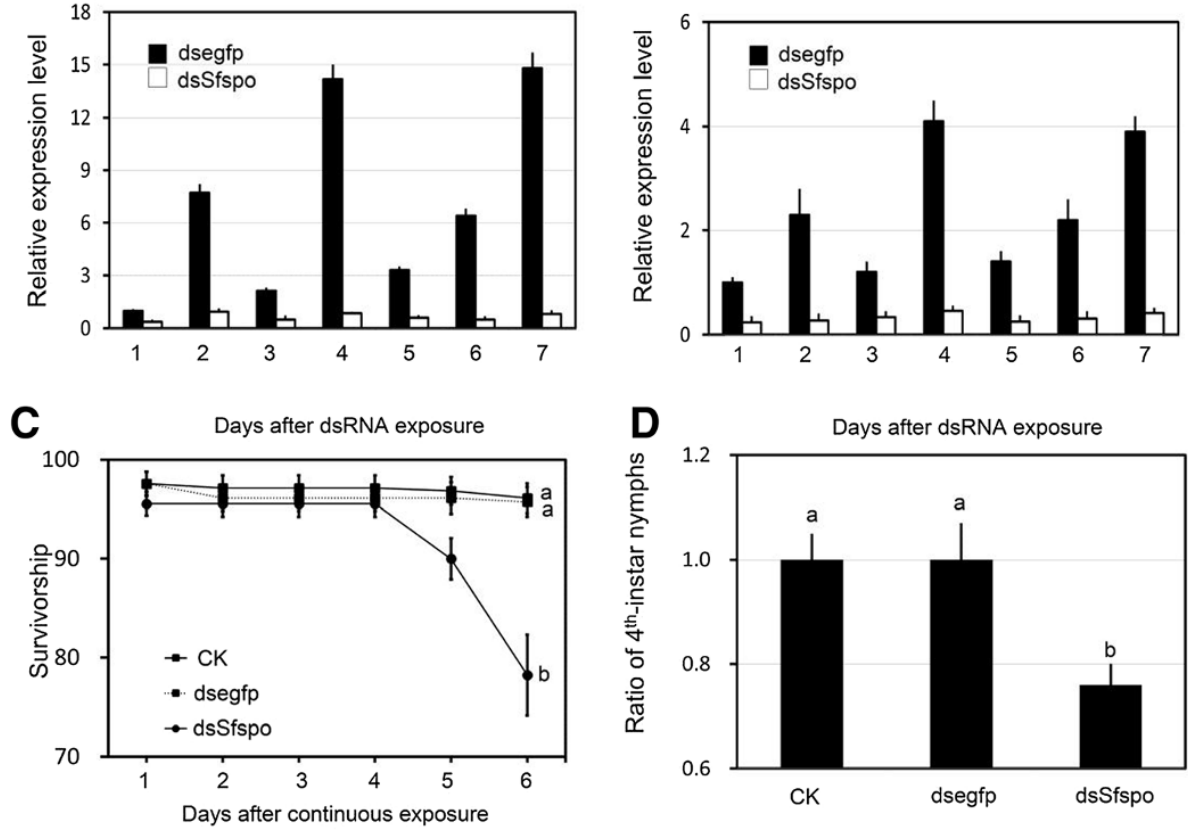

Figure 3 Effects of dietary ingestion of dsSfspo on the relative Sfspo (A) and SfEcR (B) transcript levels, survival (C) and development (D) of $L$. striatellus nymphs. The nymphs were continuously ingested dsRNA from the second-through the fourth-instar stage. The relative transcript level for each sample was measured daily from 3 independent pools of 5-10 nymphs. The survival was calculated daily from 10 biological replicates, with each replicate of 10 individuals. The percentage of the fourth-instar was estimated from those in 10 biological replicates that survived through all experimental period. The values represent averages with vertical bars indicating SE, which topped with the same letters are not statistically significantly different at $\mathrm{P}=0.05$.

resulted in lethality in most of the treated nymphs. Intriguingly, apparent wing defects in morphogenesis and melanization occurred in L. striatellus nymphs subjected to dsEcR microinjection [54].

It has long been known that topical application of $20 \mathrm{E}$ could trigger physiological response such as regulation of diapause in the fourth-instar planthopper nymphs [55]. In the present paper, we tested whether 20E could rescue the negative effects of Sfspo-dsRNA ingestion on nymphs. Our results revealed that 20E application to Sfspo-dsRNAexposed nymphs almost completely relieved the negative effects on the survival and the development. Thus, we provided the third line of evidence to support the suggestion that SfSPO plays critical roles in ecdysteroidogenesis in S. furcifera.

\section{Conclusions}

In the present paper, we cloned Sfspo and found that the conservation of SfSPO is valid in S. furcifera. Thus, SfSPO is probably also involved in ecdysteroidogenesis for hemiptera.

\section{Methods}

Insect culture and chemicals

S. furcifera adults were collected from Nanjing $\left(32.0^{\circ} \mathrm{N}\right.$, $118.5^{\circ}$ E), Jiangsu Province in China in 2010. The strain has been reared routinely on rice (Oryza sativa), in an insectary under controlled temperature $\left(28 \pm 1^{\circ} \mathrm{C}\right)$, photoperiod (16 h light $/ 8 \mathrm{~h}$ dark) and relative humidity (more than $80 \%$ ) since then, with wild stock injections every summer. Rice variety (Taichung Native 1 ) was grown in soil at $30-$ $35^{\circ} \mathrm{C}$ under a long day photoperiod ( $16 \mathrm{~h}$ light $/ 8 \mathrm{~h}$ dark) in a growth incubator. The planthoppers were transferred to fresh seedlings every 10-14 days to assure sufficient nutrition.

At laboratory reared by above protocol, S. furcifera eggs hatched into nymphs within 7 days. Nymphs went through 5 instars, with the average periods of the first-, second-, third-, fourth- and fifth-instar stages of 2.5, 2.0, 2.0, 3.0 and 3.0 days, respectively. Upon reaching full size, the fifth-instar nymphs emerged as adults.

$20 \mathrm{E}$ was purchased from Sigma, and was purified by reverse-phase HPLC before experiments.

\section{Sequence assembly and homology searches}

Raw nucleotide reads of $S$. furcifera were downloaded from the NCBI Sequence Read Archive (SRA) database with its accession number SRP009194, and assembled into unigenes using Trinity software [56]. The annotated SPO from 4 representative insect species $A$. pisum, $T$. castaneum, $M$. sexta and D. melanogaster were downloaded from NCBI reference sequences (RefSeq) database. These protein 

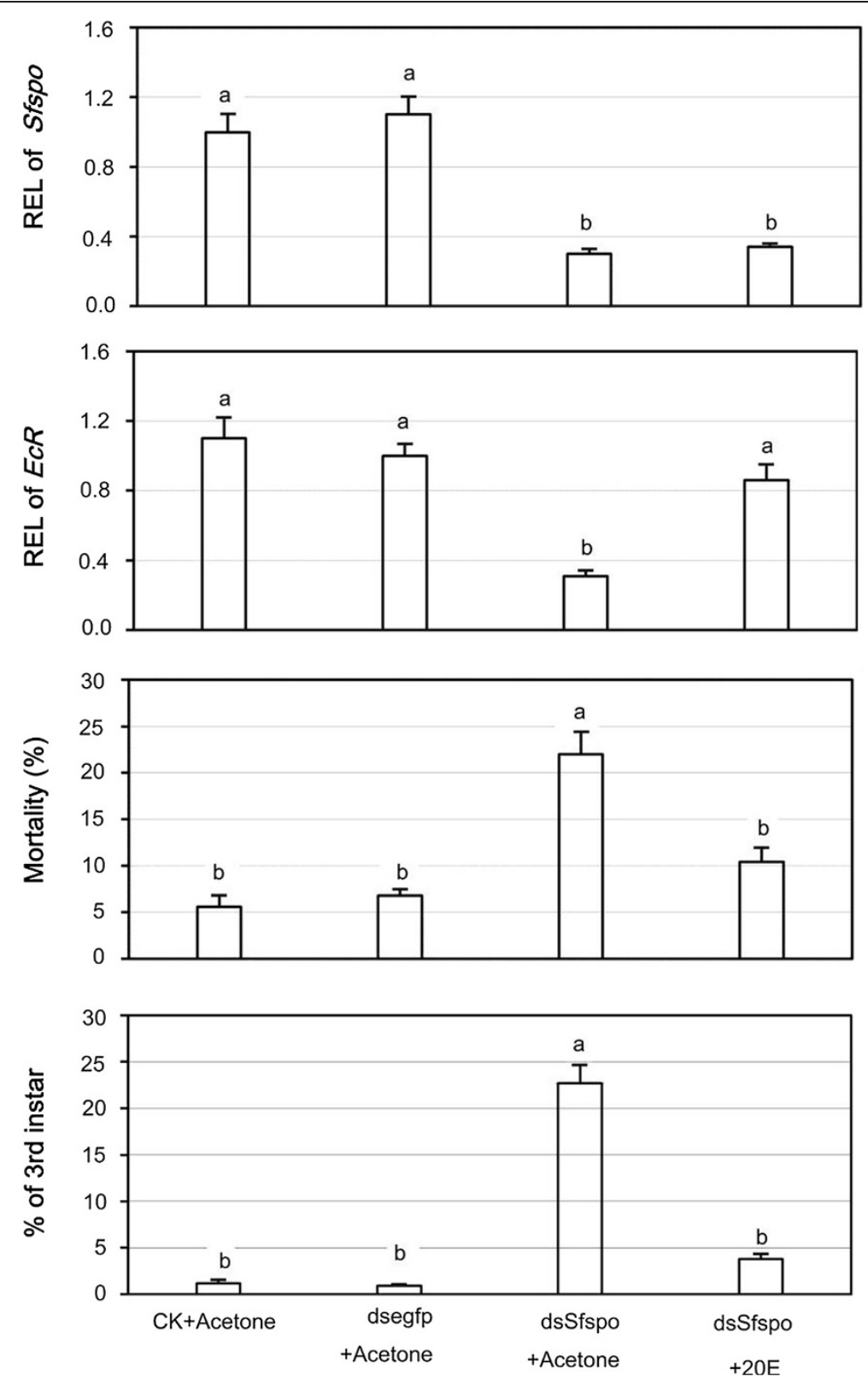

Figure 4 Relative expression level (REL) of spo and EcR gene, mortality and percentage of third-instar nymphs in S. furcifera nymphs subjected to both dsSfspo exposure and $20 \mathrm{E}$ application. The nymphs were continuously ingested dsRNA from the second-instar through the early fourth-instar stage. Two-days after dsRNA exposure, the nymphs received $0.03 \mu \mathrm{L}$ acetone or $300 \mathrm{pg}$ of $20 \mathrm{E}$ in $0.03 \mu \mathrm{L}$ acetone. The values represent averages with vertical bars indicating $\mathrm{SE}$, which topped with the same letters are not statistically different at $P=0.05$.

sequences were used for TBLASTN searches of S. furcifera transcriptome data to identify hits at a cutoff E-value of $1.0^{-5}$. The nucleotide sequences of hits resulting from initial searches were annotated by blasting (BLASTX, e-values $<10^{-5}$ ) against a local protein database containing NCBI non-redundant proteins.

\section{Molecular cloning}

Total RNA was extracted from the fourth-instar nymphs using TRIzol reagent according to the manufacturer's instructions (Invitrogen), and was treated for $30 \mathrm{~min}$ at $37^{\circ} \mathrm{C}$ with RNase free DNase I (Ambion, Austin, TX) to eliminate traces of chromosomal DNA. The purity and amount of RNA were determined by NanoDrop ND-1000 spectrophotometer (Nanodrop Technologies, Rockland, DE, USA). First-strand cDNA was synthesized from the total RNA using the reverse transcriptase (M-MLV RT) (Takara Bio., Dalian, China) and an oligo $(\mathrm{dT})_{18}$ primer, and was used as a template for polymerase chain reaction (PCR) to authenticate the sequences of the selected 
unigenes. The primers based on the sequences were designed using Primer3 software [57]. Once initial Sfspo unigenes were authenticated, they were aligned to the full cDNA sequence of the gene from the 4 representative insect species mentioned above. Some short sequence gaps between two aligned unigenes were found. Specific primers were designed based on the two unigenes between each gap, and the gaps were filled by PCR. The final cDNA sequence was authenticated using the primers listed in Table 1. Thermal cycling conditions were $94^{\circ} \mathrm{C}$ for $5 \mathrm{~min}$, followed by 35 cycles of $94^{\circ} \mathrm{C}$ for $30 \mathrm{sec}, 55^{\circ} \mathrm{C}$ for $45 \mathrm{sec}$ and $72^{\circ} \mathrm{C}$ for $3 \mathrm{~min}$. The last cycle was followed by final extension at $72^{\circ} \mathrm{C}$ for $10 \mathrm{~min}$. Each $50 \mu \mathrm{L}$ PCR reaction contained $2 \mu \mathrm{L}$ of cDNA template, $5 \mu \mathrm{L}$ of $10 \times \mathrm{LA}$ Taq buffer $\left(\mathrm{Mg}^{2+}\right.$ Free), $4 \mu \mathrm{L}$ of $\mathrm{MgCl}_{2}$ (25 mM), $4 \mu \mathrm{L}$ of dNTP mixture (2.5 mM/each), $1 \mu \mathrm{L}$ of forward and $1 \mu \mathrm{L}$ of reverse primers $(10 \mu \mathrm{M}), 0.5 \mu \mathrm{L}$ of LA Taq polymerase (Takara Bio.) $(5 \mathrm{U} / \mu \mathrm{L})$ and $32.5 \mu \mathrm{L}$ of double distilled $\mathrm{H}_{2} \mathrm{O}$.

The 5'- and 3'-RACE Ready cDNA were synthesized following the manufacturer's instructions, primed by oligo (dT) primer and the SMART II A oligonucleotide using the SMARTer RACE cDNA amplification kit (Takara Bio.). Antisense and sense gene-specific primers (Table 1) corresponding to the 5'- and 3'-end of the sequence obtained above, and the universal primers in the SMARTer RACE kit (Takara Bio.) were used to amplify the 5 '-end and the 3 '-end. The components of reaction have been described above. Thermal cycling conditions were $94^{\circ} \mathrm{C}$ for $3 \mathrm{~min}$; followed by 5 cycles of $94^{\circ} \mathrm{C}$ for $30 \mathrm{sec}, 72^{\circ} \mathrm{C}$ for $5 \mathrm{~min}$; and another 5 cycles of $94^{\circ} \mathrm{C}$ for $30 \mathrm{sec}, 70^{\circ} \mathrm{C}$ for $30 \mathrm{sec}$, $72^{\circ} \mathrm{C}$ for $5 \mathrm{~min}$; and followed by 25 cycles of $94^{\circ} \mathrm{C}$ for $30 \mathrm{sec}, 68^{\circ} \mathrm{C}$ for $30 \mathrm{sec}, 72^{\circ} \mathrm{C}$ for $5 \mathrm{~min}$. The last cycle was followed by final extension at $72^{\circ} \mathrm{C}$ for $10 \mathrm{~min}$.

The amplified product was separated by $1.2 \%$ agarose gel and purified with Wizard DNA Gel Extraction Kit (Promega, Madison, Wis., USA), and then cloned into pGEM-T easy vector (Promega). Several independent subclones were sequenced on an Applied Biosystems 3730 automated sequencer (Applied Biosystems, Foster City, Calif., USA) from both directions.

After full-length cDNA was obtained, we designed primers (Table 1 ) to verify the complete ORF with the same PCR conditions outlined above. ORF was predicted using the editseq program of DNAStar (http://www.dnastar.com) and the features of the protein were determined by TargetP. The resulting sequence was submitted to GenBank (KC579454). The annotated SPO-like proteins from the 4 representative insect species mentioned above were aligned with the predicted LsSPOK using ClustalW2.1 [58].

\section{Preparation of dsRNA}

A 415 bp cDNA sequence of $S f s p o$ and a 414 bp fragment of enhanced green fluorescent protein gene $e g f p$ (control) were individually subcloned into pEASY-T3
Table 1 Primers used in RT-PCR, 5' and 3' RACE, synthesizing dsRNA, and performing qRT-PCR

\begin{tabular}{|c|c|c|}
\hline Primer & Sequence $\left(5^{\prime}\right.$ to $\left.3^{\prime}\right)$ & Amplicon size (bp) \\
\hline \multicolumn{3}{|c|}{ Primers used in RT-PCR } \\
\hline spoFp & ACGGCCAGTCCATTTCAG & 344 \\
\hline spoRp & TGTTGGATGAGGCAGTCG & \\
\hline \multicolumn{3}{|c|}{ Primers used in $5^{\prime}$-RACE } \\
\hline spoGSP & GATGCCAAGTGAGGGTGGGATC & \\
\hline spoNGSP & TCGGTGAAGTCTITGGGCTCGG & \\
\hline \multicolumn{3}{|c|}{ Primers used in $3^{\prime}$ RACE } \\
\hline spoGSP & ACGCGACATTCGCCGCTTTGTG & \\
\hline spoNGSP & CGATGCGCTGCTCGCTCACCTT & \\
\hline \multicolumn{3}{|c|}{ Primers used in PCR for End to End } \\
\hline spoFp & CGTCGTGAACACCCTTAT & 2090 \\
\hline spoRp & GCCCGGTACACTATTATCTT & \\
\hline \multicolumn{3}{|c|}{ Synthesizing the dsRNAs } \\
\hline spoFd & CCCTCACTTGGCATCAC & 415 \\
\hline spoRd & TCGGGTTTCTTATITGTC & \\
\hline egfpup & AAGTTCAGCGTGTCCG & 414 \\
\hline egfpdown & CTTGCCGTAGTTCCAC & \\
\hline \multicolumn{3}{|c|}{ Performing the $\mathrm{qPCR}$} \\
\hline spoFq & CAACTCCATACACATCAAGCCACTG & 119 \\
\hline spoRq & ACCGACGCACCATATCTCTGAAC & \\
\hline EcRFq & AATGAGTTCGAGCACCCTAGCGAA & 129 \\
\hline EcRRq & AATGGTGATTTCGGTGATGTGGCG & \\
\hline RPL9Fq & TGTGTGACCACCGAGAACAACTCA & 131 \\
\hline RPL9Rq & ACGATGAGCTCGTCCTTCTGCTTT & \\
\hline ARFFq & CACAATATCACCGACTITGGGATTC & 141 \\
\hline ARFRq & CAGATCAGACCGTCCGTACTCTC & \\
\hline
\end{tabular}

vector (TransGen Biotech, Beijing, China), and the diluted plasmids were used as templates for amplification of these target sequences by PCR, using specific primers (Table 1 ) conjugated with the T7 RNA polymerase promoter (5'-taatacgactcactataggg-3') and the PCR conditions described above. The PCR products were purified with Wizard H SV Gel (Promega) and used as templates for dsRNA synthesis with the T7 Ribomax TM Express RNAi System, according to the manufacturer's instructions (Promega). The reaction products were treated with RNase and DNase I to degrade single-strand RNA and DNA template, respectively, at $37^{\circ} \mathrm{C}$ for one hour, following manufacturer's directions. The synthesized dsRNA was isopropanol precipitated, resuspended in Nuclease-free water, and quantified by a spectrophotometer (NanoDrop TM 1000) at $260 \mathrm{~nm}$. The purity and integrity were determined by agarose gel electrophoresis. The dsRNA stocks can be stored for several weeks at $-80^{\circ} \mathrm{C}$ until use. 


\section{Bioassay}

Previously reported dietary dsRNA-introducing procedure [38,39] was used, with small modifications. Briefly, glass cylinders, $12 \mathrm{~cm}$ in length and $2.8 \mathrm{~cm}$ in internal diameter, were used as feeding chambers. Twenty first-instar nymphs were carefully transferred into each chamber and prereared for one day to the second-instar stage, on liquid artificial diet (according to Dr. Fu et al. [59]) between two layers of stretched Parafim M (Pechiney Plastic Packaging Company, Chicago, IL, USA) that was placed at both ends of the chamber. The artificial diet containing one of the dsRNAs at the concentration of $0.5 \mathrm{mg} / \mathrm{ml}[38,39]$ were then used to feed the second-instar nymphs. The diet was changed and dead nymphs were removed daily.

Two experiments were carried out. The first had three treatments including non-dsRNA diet (blank control), dsegfp diet (negative control) and dsSfspo diet. The experiment lasted for 6 days. The second bioassay was a rescue experiment. Since topical application of $300 \mathrm{pg}$ of $20 \mathrm{E}$ was enough to trigger physiological response in the fourthinstar planthopper nymphs [55], $300 \mathrm{pg}$ of 20E was used in the second bioassay. After exposed to dsRNA for 2 days, the nymphs were anesthetized with carbon dioxide. A $0.03 \mu \mathrm{L}$ aliquot of acetone with or without $300 \mathrm{pg}$ of $20 \mathrm{E}$ was topically applied to the dorsal thoracic surface of the nymphs with a $10-\mu \mathrm{L}$ microsyringe connected to a microapplicator (Hamilton Company, Reno, NV). And then, the nymphs were continuously exposed to dsRNA for another 4 days. There were four treatments including: (1) nymphs on non-dsRNA diet and applied acetone (blank control); (2) nymphs on dsegfp diet and applied acetone (negative control); (3) nymphs on dsSfspo diet and applied acetone; (4) nymphs on dsSfspo diet and applied 20E. All treatments in both experiments were replicated 25 times (25 chambers), and a total of 250 nymphs in each treatment were used (100 nymphs for bioassays and 150 nymphs for q-PCR).

Mortality was recorded daily. The surviving nymphs after bioassay were collected and frozen. The instars of the surviving nymphs were identified by head capsule width and the number of rhinaira (sensilla clusters) bearing on the pedicle of the antennae $[60,61]$.

\section{Real-time quantitative PCR}

Total RNA samples were prepared from the whole bodies of the of second-, third- and fourth-instar (I2D1, I2D2, I3D1, I3D2, I4D1, I4D2 and I4D3) nymphs, from the head, thorax and abdomen of I4D3 nymphs on rice, and from nymphs subjected to 6-day's bioassays, using SV Total RNA Isolation System Kit (Promega). Each sample contained 10 nymphs and repeated in biological triplicate. Purified RNA was subjected to DNase I to remove any residual DNA according to the manufacturer's instructions. In a preliminary experiment, we estimated the expression stability of four house-keeping genes (Actin; ADP-ribosylation factor, ARF; ribosomal protein RPL9; translation elongation factor $1 \alpha E F 1 \alpha$ ), and found that $A R F$ and RPL9 were the most stable house-keeping genes and selected as internal controls. The primers of the Halloween genes Sfspo, EcR gene, ARF and RPL9 were designed with Beacon Designer 7 (Table 1). Putative mRNA abundance of Sfspo the Halloween and EcR genes in each nymphal sample was estimated by qPCR using SYBR Premix Ex Taq ${ }^{\mathrm{Tm}}$ (Perfect Real Time) (Takara Bio.) and ABI 7500 Real-Time PCR System (Applied Biosystems) according to the manufacturer's instruction. The reaction mixture consisted of $2 \mu \mathrm{L}$ of cDNA template (corresponding to $50 \mathrm{ng}$ of the starting amount of RNA), $10 \mu \mathrm{L}$ of SYBR Premix Ex Taq (Takara Bio.), $1 \mu \mathrm{L}$ of forward primer $(10 \mu \mathrm{M}), 1 \mu \mathrm{L}$ of reverse primer $(10 \mu \mathrm{M}), 0.4 \mu \mathrm{L}$ of Rox Reference Dye $(50 \times)$ in a final reaction volume of $20 \mu \mathrm{L}$. A reverse transcription negative control (without reverse transcriptase) and a non-template negative control were included for each primer set to confirm the absence of genomic DNA and to check for primer-dimer or contamination in the reactions, respectively. The following standard qPCR protocol was used: denaturing at $95^{\circ} \mathrm{C}$ for $30 \mathrm{sec}$, followed by 40 cycles of $95^{\circ} \mathrm{C}$ for $5 \mathrm{sec}$ and $60^{\circ} \mathrm{C}$ for $34 \mathrm{sec}$. After amplification, the melting curves were determined by heating the sample up to $95^{\circ} \mathrm{C}$ for $15 \mathrm{sec}$, followed by cooling down to $60^{\circ} \mathrm{C}$ for $1 \mathrm{~min}$, and heating the samples to $95^{\circ} \mathrm{C}$ for $15 \mathrm{sec}$.

The generation of specific PCR products was confirmed by sequencing and gel electrophoresis. Each primer pair was tested with a 10-fold logarithmic dilution of a cDNA mixture to generate a linear standard curve (crossing point CP plotted vs. log of template concentration), which was used to calculate the primer pair efficiency. All experiments were repeated in technical triplicate. Data were analyzed by the $2^{-\Delta \Delta C t}$ method [62], using the geometric mean of $A R F 1$ and RP18 for normalization according to the strategy described previously $[62,63]$.

\section{Data analysis}

The data were given as means $\pm \mathrm{SE}$, and were analyzed by ANOVAs or a repeated measures ANOVA followed by the Tukey-Kramer test, using SPSS for Windows (SPSS, Chicago, IL, USA).

\section{Abbreviations}

PCR: Polymerase chain reaction; RT-PCR: Reverse transcriptase PCR; qRT-PCR: Quantitative real-time PCR; CDNA: Complementary DNA; CYP: Cytochrome P450 monooxygenase; dsRNA: Double-stranded RNA; EcR: Ecdysone receptor; E: Ecdysone; 20E: 20-Hydroxyecdysone;

YLS: Yeast-like symbionts; RNAi: RNA interference; ORF: Open reading frame; ML: Maximum-likelihood; SE: Standard error; ANOVA: Analysis of variance.

\section{Competing interests}

The authors declare that they have no competing interests. 


\section{Authors' contributions}

SJ and PJW performed most of the experimental procedures, and data analysis. LTZ and LLM performed partial experiments, assisted in manuscript revising and provided helpful discussions. GQL wrote the manuscript, conceived and supervised the research. All authors read and approved the final manuscript.

\section{Acknowledgments}

This research was supported by the National Basic Research Program of China (973 Program, No. 2010CB126200). We thank Drs Z. Han, and S. Dong of our laboratory for useful discussions during the course of this research.

Received: 22 March 2013 Accepted: 26 August 2013

Published: 4 September 2013

\section{References}

1. Iga $\mathrm{M}$, Kataoka $\mathrm{H}$ : Recent studies on insect hormone metabolic pathways mediated by cytochrome P450 enzymes. Biol Pharm Bull 2012, 35(6):838-843.

2. Behmer ST, David Nes W: Insect sterol nutrition and physiology: a global overview. Advances in insect physiology 2003, 31:1-72.

3. Chen CC, Cheng LL, Hou RF: Studies on the intracellular yeast-like symbiote in the brown planthopper, Nilaparvata lugens Stal. J Appl Entomol 1981, 92:440-449.

4. Pang K, Dong S-Z, Hou Y, Bian Y-L, Yang K, Yu X-P: Cultivation, identification and quantification of one species of yeast-like symbiotes, Candida, in the rice brown planthopper, Nilaparvata lugens. Insect Sci 2012, 19(4):477-484.

5. Dong SZ, Pang K, Bai X, Yu XP, Hao PY: Identification of two species of yeast-like symbiotes in the brown planthopper, Nilaparvata lugens. Curr Microbiol 2011, 62(4):1133-1138.

6. Noda H, Saito T: The role of intracelular yeastlike symbiotes in the development of Laodelphax striatellus (Homoptera: Delphacidae). Appl Environ Microbiol 1979, 14:453-458.

7. Noda H, Saito T: Histological and histochemical observation of intracellular yeastlike symbiotes in the fat body of the smaller brown planthopper, Laodelphax striatellus (Homoptera: Delphacidae). Applied Entomology and Zoology 1977, 12:134-141.

8. Noda H: Preliminary histological observation and population dynamics of intracellular yeast-like symbiotes in the smaller brown planthopper, Laodelphax striatellus (Homoptera: Delphacidae). Applied Entomology and Zoology 1974, 9:275-277.

9. Noda H, Wada K, Saito T: Sterols in Laodelphax striatellus with special reference to the intracellular yeastlike symbiotes as a sterol source. J Insect Physiol 1979, 25(5):443-447.

10. Eya BK, Kenny PT, Tamura SY, Ohnishi M, Naya Y, Nakanishi K, Sugiura M: Chemical association in symbiosis, Sterol donors in planthoppers. J Chem Ecol 1989, 15(1):373-380.

11. Wetzel JM, Ohnishi M, Fujita T, Nakanishi K, Naya Y, Noda H, Sugiura M: Diversity in steroidogenesis of symbiotic microorganisms from planthoppers. J Chem Ecol 1992, 18(11):2083-2094

12. Noda H, Koizumi Y: Sterol biosynthesis by symbiotes: cytochrome P450 sterol C-22 desaturase genes from yeastlike symbiotes of rice planthoppers and anobiid beetles. Insect Biochem Mol Biol 2003, 33(6):649-658.

13. Yoshiyama T, Namiki T, Mita K, Kataoka H, Niwa R: Neverland is an evolutionally conserved Rieske-domain protein that is essential for ecdysone synthesis and insect growth. Development 2006, 133:2565-2574.

14. Yoshiyama-Yanagawa T, Enya S, Shimada-Niwa Y, Yaguchi S, Haramoto $Y$, Matsuya T, Shiomi K, Sasakura Y, Takahashi S, Asashima M: The conserved rieske oxygenase DAF-36/neverland is a novel cholesterol-metabolizing enzyme. J Biol Chem 2011, 286(29):25756-25762

15. Gilbert LI, Warren JT: A molecular genetic approach to the biosynthesis of the insect steroid molting hormone. Vitam Horm 2005, 73:31-57.

16. Namiki T, Niwa R, Sakudoh T, Shirai K, Takeuchi H, Kataoka H: Cytochrome P450 CYP307A1/Spook: a regulator for ecdysone synthesis in insects. Biochemical and Biophysical Research Communication 2005, 337:367-374.

17. Ono H, Rewitz KF, Shinoda T, Itoyama K, Petryk A, Rybczynski R, Jarcho M, Warren $\pi$, Marqués G, Shimell MJ: Spook and Spookier code for stage-specific components of the ecdysone biosynthetic pathway in Diptera. Dev Biol 2006, 298(2):555-570.
18. Ou Q, Magico A, King-Jones K: Nuclear receptor DHR4 controls the timing of steroid hormone pulses during Drosophila development. PLOS Biol 2011, 9(9):e1001160.

19. Ono H, Morita S, Asakura I, Nishida R: Conversion of 3-oxo steroids into ecdysteroids triggers molting and expression of 20E-inducible genes in Drosophila melanogaster. Biochem Biophys Res Commun 2012, 421(3):561-566.

20. Luan J-B, Ghanim M, Liu S-S, Czosnek H: Silencing the ecdysone synthesis and signaling pathway genes disrupts nymphal development in the whitefly. Insect Biochem Mol Biol 2013, 43(8):740-746.

21. Hentze JL, Moeller ME, Jørgensen AF, Bengtsson MS, Bordoy AM, Warren JT, Gilbert LI, Andersen O, Rewitz KF: Accessory gland as a site for prothoracicotropic hormone controlled ecdysone synthesis in adult male insects. PLoS One 2013, 8(2):e55131.

22. Yamazaki Y, Kiuchi M, Takeuchi H, Kubo T: Ecdysteroid biosynthesis in workers of the European honeybee Apis mellifera L. Insect Biochem Mol Biol 2011, 41(5):283-293.

23. Iga M, Smagghe G: Identification and expression profile of Halloween genes involved in ecdysteroid biosynthesis in Spodoptera littoralis. Peptides 2010, 31(3):456-467.

24. Zhou J, Zhang H, Li J, Sheng X, Zong S, Luo Y, Weng Q: Molecular cloning and expression profile of a Halloween gene encoding CYP307A1 from the seabuckthorn carpenterworm, Holcocerus hippophaecolus. J Insect Sci 2012, 13:56.

25. Marchal E, Badisco L, Verlinden H, Vandersmissen T, Van Soest S, Van Wielendaele P, Vanden Broeck J: Role of the Halloween genes, Spook and Phantom in ecdysteroidogenesis in the desert locust, Schistocerca gregaria. J Insect Physiol 2011, 57(9):1240-1248.

26. Christiaens $O$, Iga M, Velarde R, Rougé P, Smagghe G: Halloween genes and nuclear receptors in ecdysteroid biosynthesis and signalling in the pea aphid. Insect Mol Biol 2010, 19:187-200.

27. Tan A, Palli SR: Edysone receptor isoforms play distinct roles in controlling molting and metamorphosis in the red flour beetle, Tribolium castaneum. Mol Cell Endocrinol 2008, 291(1):42-49.

28. Wu W-J, Wang Y, Huang H-J, Bao Y-Y, Zhang C-X: Ecdysone receptor controls wing morphogenesis and melanization during rice planthopper metamorphosis. J Insect Physiol 2012, 58(3):420-426.

29. Karim FD, Thummel C: Temporal coordination of regulatory gene expression by the steroid hormone ecdysone. EMBO J 1992, 11(11):4083-4093.

30. Varghese J, Cohen SM: microRNA miR-14 acts to modulate a positive autoregulatory loop controlling steroid hormone signaling in Drosophila. Science 2007, 21(18):2277-2282.

31. Matusmura M, Sanada-Morimura S: Recent status of insecticide resistance in Asian rice planthoppers. Japan Agricultural Research Quarterly 2010, 44(3):225-230

32. Zhang $P$, Mar TT, Liu W, Li L, Wang X: Simultaneous detection and differentiation of Rice black streaked dwarf virus (RBSDV) and Southern rice black streaked dwarf virus (SRBSDV) by duplex real time RT-PCR. Virol J 2013, 10(1):24.

33. Matsukura K, Towata T, Sakai J, Onuki M, Okuda M, Matsumura M: Dynamics of Southern rice black-streaked dwarf virus in rice and implication for virus acquisition. Phytopathology 2013. doi:10.1094/PHYTO-10-12-0261-R(ja).

34. Fujita D, Kohli A, Horgan FG: Rice resistance to planthoppers and leafhoppers. Crit Rev Plant Sci 2013, 32(3):162-191.

35. Xu Y, Zhou W, Zhou Y, Wu J, Zhou X: Transcriptome and comparative gene expression analysis of Sogatella furcifera (Horváth) in response to southern rice black-streaked dwarf virus. PLoS One 2012, 7(4):e36238.

36. Zha W, Peng X, Chen R, Du B, Zhu L, He G: Knockdown of midgut genes by dsRNA-transgenic plant-mediated RNA interference in the hemipteran insect Nilaparvata lugens. PLoS One 2011, 6(5):e20504.

37. Li J, Chen QH, Lin YJ, Jiang TR, Wu G, Hua HX: RNA interference in Nilaparvata lugens (Homoptera: Delphacidae) based on dsRNA ingestion. Pest Manag Sci 2011, 67(7):852-859.

38. Chen J, Zhang D, Yao Q, Zhang J, Dong X, Tian H, Zhang W: Feeding-based RNA interference of a trehalose phosphate synthase gene in the brown planthopper, Nilaparvata lugens. Insect Mol Biol 2010, 19(6):777-786.

39. He P, Zhang J, Liu NY, Zhang YN, Yang K, Dong SL: Distinct expression profiles and different functions of odorant binding proteins in Nilaparvata lugens Stål. PLoS One 2011, 6(12):e28921. 
40. Werck-Reichhart D, Feyereisen R: Cytochromes P450: a success story. Genome Biol 2000, 1(6):reviews 3003.3001-3009.

41. Petryk A, Warren JT, Marqués G, Jarcho MP, Gilbert LI, Kahler J, Parvy JP, Li Y, Dauphin-Villemant C, O'Connor MB: Shade is the Drosophila P450 enzyme that mediates the hydroxylation of ecdysone to the steroid insect molting hormone 20-hydroxyecdysone. Proc Natl Acad Sci USA 2003, 100(24):13773-13778.

42. Rewitz KF, Rybczynski R, Warren JT, Gilbert LI: Developmental expression of Manduca shade, the P450 mediating the final step in molting hormone synthesis. Mol Cell Endocrinol 2006, 247(1-2):166-174.

43. Rewitz KF, Rybczynski R, Warren JT, Gilbert Ll: The Halloween genes code for cytochrome P450 enzymes mediating synthesis of the insect moulting hormone. Biochem Soc Trans 2006, 34:1256-1260

44. Yamazaki Y, Kiuchi M, Takeuchi H, Kubo T: Ecdysteroid biosynthesis in workers of the European honeybee Apis mellifera L. Insect Biochem Mol Biol 2011, 41:283-293.

45. Rewitz K, Gilbert L: Daphnia Halloween genes that encode cytochrome P450s mediating the synthesis of the arthropod molting hormone: Evolutionary implications. BMC Evol Biol 2008, 8(1):60.

46. Warren JT, Petryk A, Marqués G, Parvy JP, Shinoda T, Itoyama K, Kobayashi J, Jarcho M, Li Y, O'Connor MB: Phantom encodes the 25-hydroxylase of Drosophila melanogaster and Bombyx mori: a P450 enzyme critical in ecdysone biosynthesis. Insect Biochem Mol Biol 2004, 34(9):991-1010.

47. Kobayashi M, Uchida M, Kuriyama K: Elevation of 20-hydroxyecdysone level by buprofezin in Nilaparvata lugens Stål nymphs. Pestic Biochem Physiol 1989, 34(1):9-16.

48. Niwa R, Matsuda T, Yoshiyama T, Namiki T, Mita K, Fujimoto $Y$, Kataoka $H$ : CYP306A1, a cytochrome P450 enzyme, is essential for ecdysteroid biosynthesis in the prothoracic glands of Bombyx and Drosophila. J Biol Chem 2004, 279(34):35942-35949.

49. Chávez VM, Marqués G, Delbecque JP, Kobayashi K, Hollingsworth M, Burr J, Natzle JE, O'Connor MB: The Drosophila disembodied gene controls late embryonic morphogenesis and codes for a cytochrome P450 enzyme that regulates embryonic ecdysone levels. Development 2000, 127(19):4115-4126.

50. Niwa R, Sakudoh T, Namiki T, Saida K, Fujimoto Y, Kataoka H: The ecdysteroidogenic P450 Cyp302a1/disembodied from the silkworm, Bombyx mori, is transcriptionally regulated by prothoracicotropic hormone. Insect Mol Biol 2005, 14(5):563-571.

51. Warren JT, Petryk A, Marqués G, Jarcho M, Parvy JP, Dauphin-Villemant C, $\mathrm{O}^{\prime}$ Connor MB, Gilbert LI: Molecular and biochemical characterization of two P450 enzymes in the ecdysteroidogenic pathway of Drosophila melanogaster. Proc Natl Acad Sci USA 2002, 99(17):11043-11048.

52. Varghese J, Cohen SM: microRNA miR-14 acts to modulate a positive autoregulatory loop controlling steroid hormone signaling in Drosophila. Science Signalling 2007, 21(18):2277-2282.

53. Tan AJ, Palli SR: Edysone receptor isoforms play distinct roles in controlling molting and metamorphosis in the red flour beetle, Tribolium castaneum. Mol Cell Endocrinol 2008, 291:42-49.

54. Wu WJ, Wang Y, Huang HJ, Bao YY, Zhang CX: Ecdysone receptor controls wing morphogenesis and melanization during rice planthopper metamorphosis. J Insect Physiol 2012, 58:420-426.

55. Miyake T, Haruyama H, Mitsui T, Sakurai A: Effects of a new juvenile hormone mimic, NC-170, on metamorphosis and diapause of the small brown planthopper, Laodelphax striatellus. J Pestic Sci 1992, 17(1):75-82.

56. Grabherr MG, Haas BJ, Yassour M, Levin JZ, Thompson DA, Amit I, Adiconis $X$, Fan L, Raychowdhury R, Zeng Q, et al: Full-length transcriptome assembly from RNA-Seq data without a reference genome. Nat Biotechnol 2011, 29(7):644-652.

57. Rozen S, Skaletsky H: Primer3 on the WWW for general users and for biologist programmers. Methods Mol Biol 2000, 132(3):365-386.

58. Larkin MA, Blackshields G, Brown NP, Chenna R, McGettigan PA, McWilliam $H$, Valentin F, Wallace IM, Wilm A, Lopez R, et al: Clustal W and Clustal X version 2.0. Bioinformatics 2007, 23(21):2947-2948.

59. Fu Q, Zhang Z, Hu C, Lai F, Sun Z: A chemically defined diet enables continuous rearing of the brown planthopper, Nilaparvata lugens (Stål) (Homoptera: Delphacidae). Applied Entomology and Zoology 2001, 36(1):111-116.

60. Sun HX, Hu XJ, Shu YH, Zhang GR: Observation on the antennal sensilla of Sogatella furcifera (Horváth) (Homoptera: Delphacidae) with scanning electron microscope. Acta Entomologica Sinica 2006, 49(2):349-354.
61. Ding JH, Hu CL, Fu Q, He JC, Xie MC: A colour atlas of commonly encountered delphacidae in china rice regions. HangZhou, China: HangZhou Science and Technology Press; 2012:10-26.

62. Pfaffl MW: A new mathematical model for relative quantification in real-time RT-PCR. Nucleic Acids Res 2001, 29:e45

63. Vandesompele J, De Preter K, Pattyn F, Poppe B, Van Roy N, De Paepe A, Speleman F: Accurate normalization of real-time quantitative RT-PCR data by geometric averaging of multiple internal control genes. Genome Biol 2002, 3:RESEARCH0034.

doi:10.1186/1471-2199-14-19

Cite this article as: Jia et al:: Molecular cloning and RNA interferencemediated functional characterization of a Halloween gene spook in the white-backed planthopper Sogatella furcifera. BMC Molecular Biology 2013 14:19.

\section{Submit your next manuscript to BioMed Central and take full advantage of:}

- Convenient online submission

- Thorough peer review

- No space constraints or color figure charges

- Immediate publication on acceptance

- Inclusion in PubMed, CAS, Scopus and Google Scholar

- Research which is freely available for redistribution 